\section{Hold-'Em In Place}

Kristen R. Ross and Michael E. Berens

Barrow Neurological Institute

kross@chw.edu or mberens@CHW.EDU

We've used gelled agarose to cover \& hold monolayer cells in place when treatment leads to cell lifting. Low-gelling temperature agarose (Type VII) (Sigma A 4018 or A 0701) can be made as a $2 \%$ stock solution in "phosphate-buffered saline" (PBS) (boiled then kept at $42^{\circ} \mathrm{C}$ to remain liquid). The agarose can be stored at room temperature at this time, but must be boiled and melted again before use.

1) Immediately before applying to the cells (with the experimental and/or control treatment), dilute the stock to a final agarose concentration of $0.8 \%$ in $2 \mathrm{X}$ culture media $\left(37^{\circ} \mathrm{C}\right)$ appropriate for the cells.

2) Apply a volume of the agarose solution to the monolayer, incubate approximately 5 minutes at room temperature or briefly at $4^{\circ} \mathrm{C}$ to gel the agarose.

3) Transfer the slide to the incubator to keep the cells metabolically active.

The slides used for this application are very important. Teflon masked slides from Erie Scientific (Portsmouth, NH 1 800-258-0834) proved to be the most useful as they create wells without a gasket. However, the agarose forms a bubble in each well and prevents quality visualization. To circumvent this issue, we used an optics kit form CSM, Inc. (Phoenix, AZ; http://creative-sci.com). The kit includes a mechanism to suspend a coverslide over the bubble of agarose which eliminates

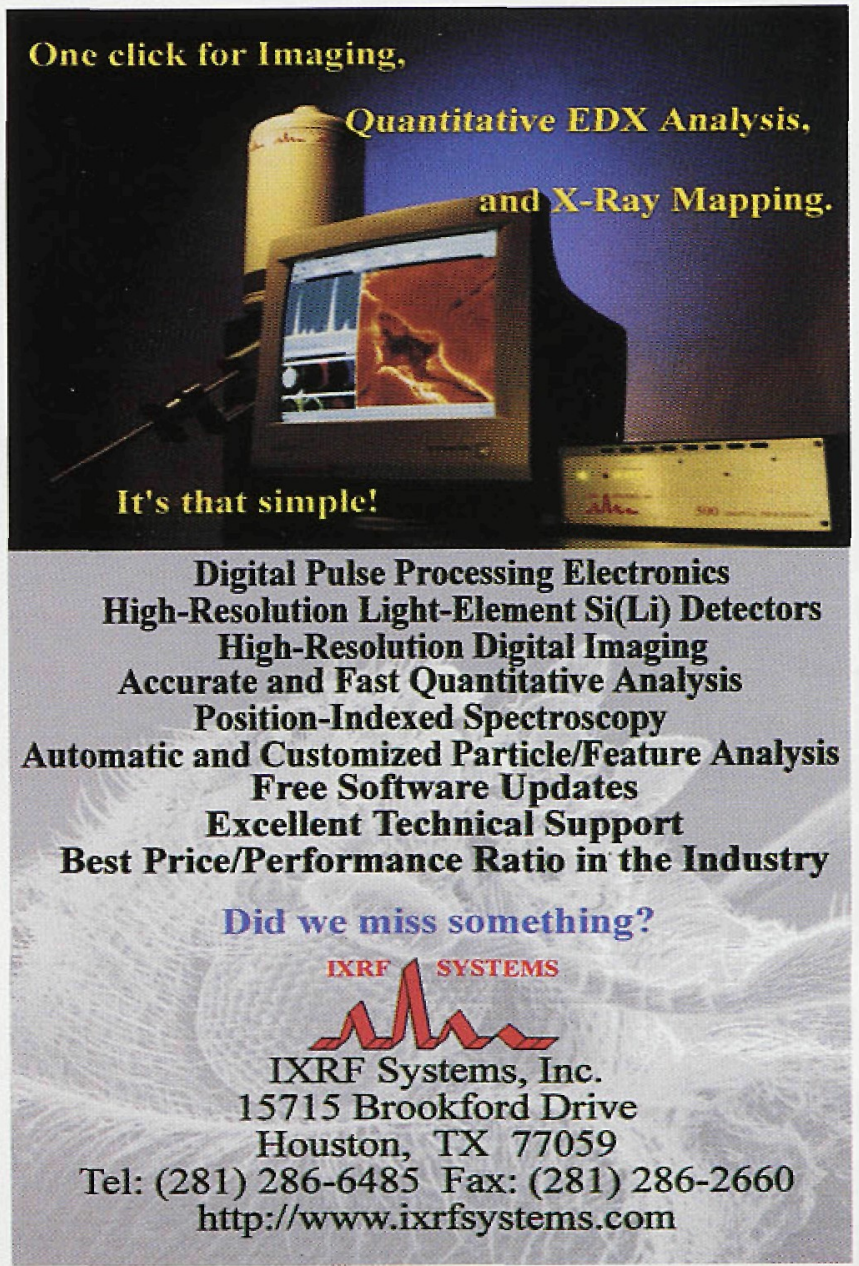

the distortion and does not put pressure on the cells. The optics kit was placed on the agarose just after application and BEFORE it gelled. As a unit, the two separated slides, with the gel in between them, were allowed to sit at room temperature (or placed in the refrigerator very briefly) to allow the agarose to cool and gel. It should also be noted that the temperature of the agarose/media solution cannot drop below $37^{\circ} \mathrm{C}$ and therefore, temperature must be monitored carefully.

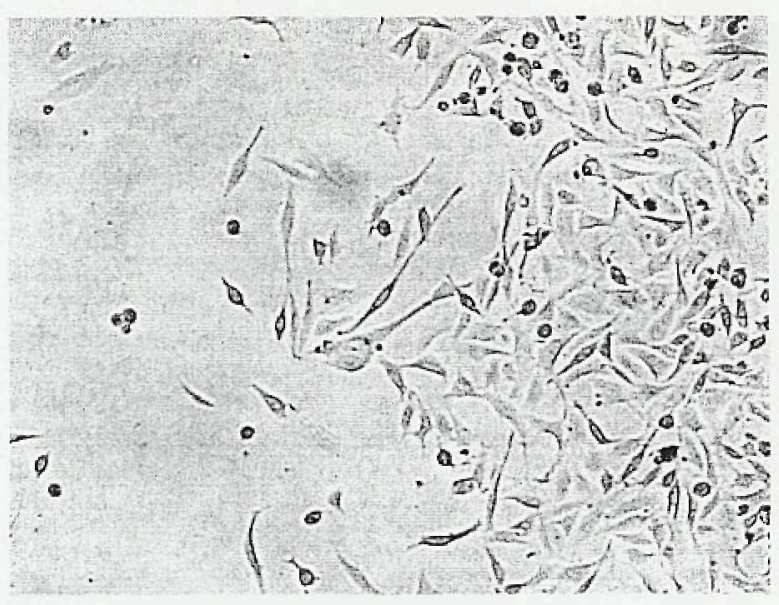

Figure 1. Untreated cells growing in MEM $+10 \%$ FBS media

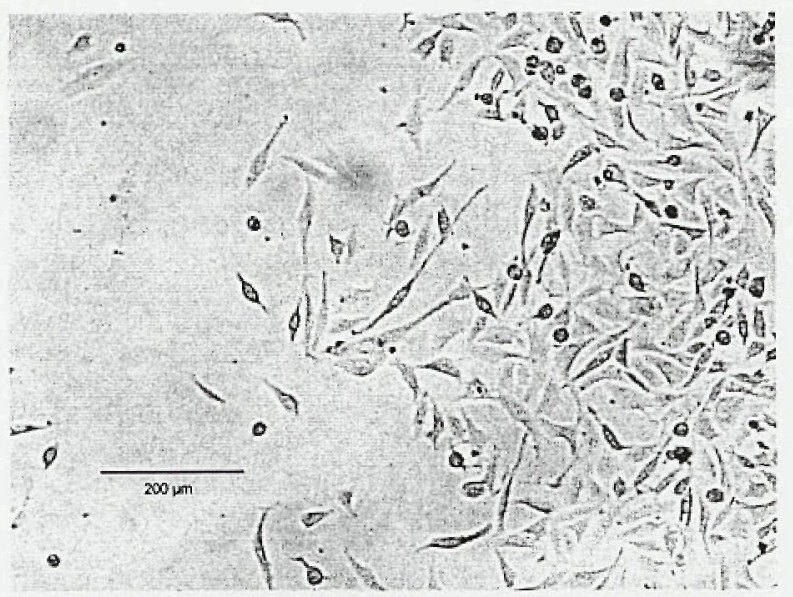

Figure 2. The same cells under $0.5 \%$ agarose (Sigma, type VII, cat\# A-4018) before $\mathrm{C} 2$ ceramide $(100 \mathrm{ng} / \mathrm{mL})$ has taken effect.

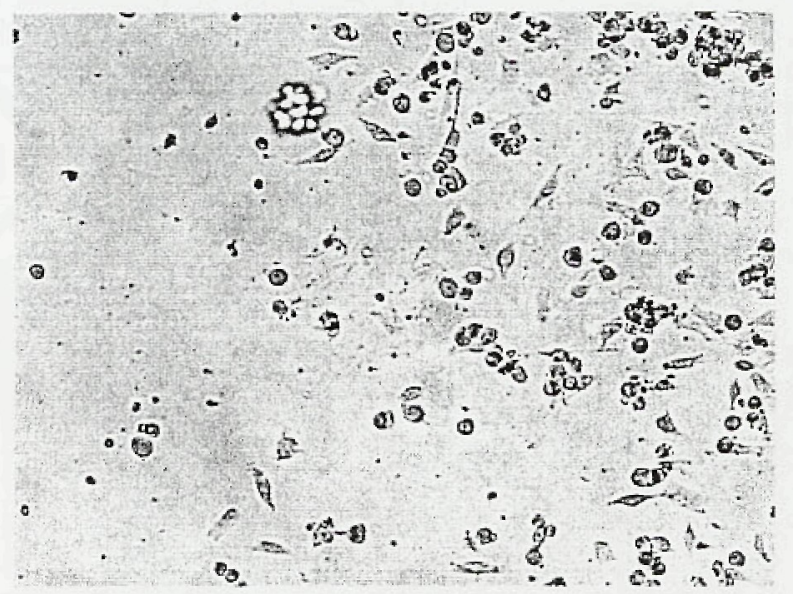

Figure 3. The same cells under $0.5 \%$ agarose after 1.5 hours treatment with $\mathrm{C} 2$ ceramide. The rounded cells demonstrate loss of cell attachment occurring from cell death. Without the agarose, the cells would have lifted from the slide and floated away. 


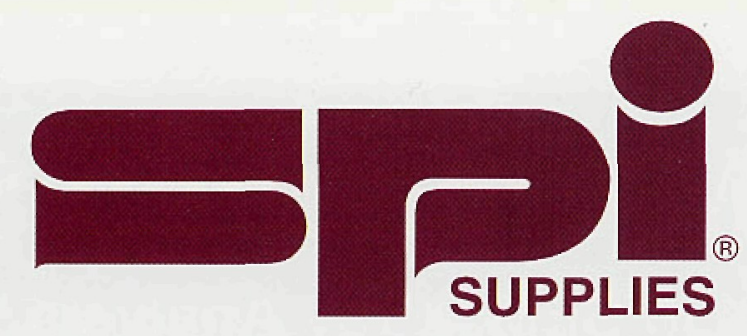

6 File Edit Diew Go Bookmarks Options Directory Help



SPI Supplies Division of STRUCTURE PROBE, Inc.

P.O. Box 656 - West Chester, PA 19381-0656 USA

Ph.: 1-610-436-5400 • 1-800-2424-SPI (U.S. only) • FAX: 1-610-436-5755 • E-mail: spi2spi@ 2spi.com 


\section{Lehigh Microscopy School Eight courses in SEM, X-ray Analysis, AEM, AFM}

for Materials Engineers, Geologists, Biologists, Polymer Scientists

\section{The World's Best SEM, AEM, SPM Courses}

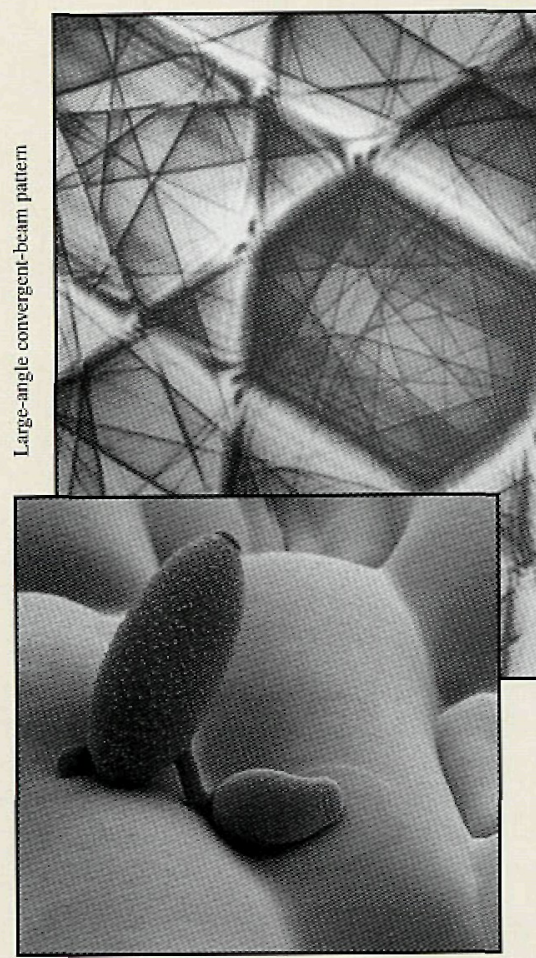

Germinating powdery mildew on a wheat leaf imaged at $5 k \mathrm{~V}$ and $-150^{\circ} \mathrm{C}$ in a Philips XL30 FEG-SEM

(courtesy of Alison Daniels, ArgEvo UK)
- http://www.lehigh.edu/microscopy

- Taken by over 4000 engineers, scientists, and technicians

- Participants have come from 48 states and 29 countries

- Free to every registrant: the Lehigh CD ROM containing software, images, and data

- Textbooks authored by the lecturers are included

\section{Scanning Electron Microscopy and X-ray Microanalysis The Lehigh Main Course} (June 11-15, 2001)

For scientists, technicians, engineers, and technical managers. Core topics: Image formation - EDS qualitative analysis specimen preparation - basic maintenance of SEMs $\bullet$ strategies for practical microscopy and microanalysis. Special Interest Options: X-ray analysis, imaging techniques, organic materials, inorganic materials. Textbook provided written by the course lecturers: Scanning Electron Microscopy and X-ray Microanalysis, Plenum Press, 1992. Notes provided for all lectures. Detailed laboratory notes which provide experimental results and worked problems will also be provided.

\section{Introduction to SEM and EDS for the New SEM Operator} (Sunday, June 10, 2001)

This course provides an introduction to the main SEM course for those who have little or no prior experience. It will introduce scanning electron microscopy and energy-dispersive $\mathrm{x}$-ray analysis at a very practical "knob-twisting" level. Enrollment is limited to 60 participants who are also attending the main SEM course beginning on Monday, June 11.

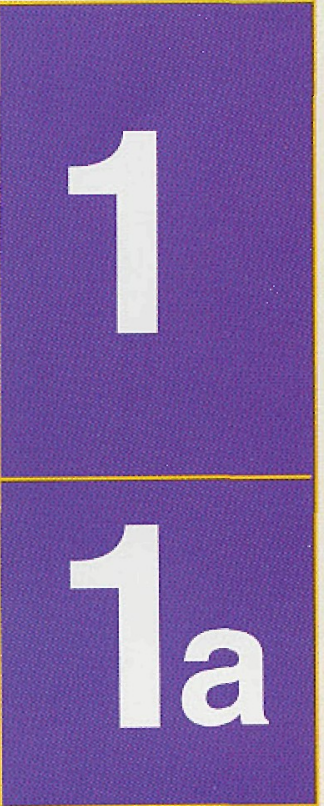




\section{Advanced Scanning Electron Microscopy \\ with Digital Image Processing}

(June 18-22, 2001)

Advanced treatment of high resolution SEM • low voltage SEM • environmental SEM • digital image processing - Monte Carlo simulations of beam-specimen interactions • electron detectors • quantitative stereo microscopy $\bullet$ stereology $\bullet$ image processing with personal computers

\section{Quantitative X-ray Microanalysis} of Bulk Specimens and Thin Films on Substrates (June 18-22, 2001)

Advanced topics include: ZAF and $\phi(\rho z)$ calculations using personal computers - WDS and EDS detectors $\cdot$ quantitative analysis of thin films, particles, and rough specimens $\bullet$ light element analysis $\bullet$ trace element analysis $\bullet$ strategies for applying microanalysis techniques $\bullet$ specimen preparation

\section{Analytical Electron Microscopy: Analysis Methods for TEM Specimens (June 18-21, 2001))}

Advanced topics include: STEM optics $\bullet$ beam-specimen interactions $\cdot Z$-contrast $\cdot \mathrm{x}$-ray microanalysis $\cdot$ electron energy-loss spectrometry $\bullet$ compositional imaging $\cdot$ convergent-beam electron diffraction - symmetry determination $\cdot$ microcomputer calculations $\bullet$ thin specimen preparation - digital imaging Textbook provided: Transmission Electron Microscopy: A Textbook for Materials Science, by D. B. Williams and C. B. Carter, Plenum, 1996

\section{TEM Specimen Preparation with Emphasis on Recent Methods (June 19-21, 2001)}

Initial thinning - review of classical final thinning methods $\bullet$ tripod polishing • low-angle ion beam milling - focused ion beam (FIB) milling • examination of typical specimens in TEM and SEM

\section{Atomic Force Microscopy} and Other Scanned Probe Microscopies (June 19-22, 2001)

Atomic force microscopy • scanning tunneling microscopy • scanning tunneling spectroscopy • feedback control - tip fabrication - tip-sample interactions • scan calibrations • in-situ imaging * UHV imaging • imaging in air and liquids • image processing • near-field optical probes $\bullet$ metrology $\cdot$ lateral-force microscopy $\cdot$ electrochemical STM/AFM • other emerging scanned probe techniques 